\title{
Glucose Modulates Rat Substantia Nigra GABA Release In Vivo via ATP-sensitive Potassium Channels
}

\author{
Matthew J. During, ${ }^{\star \ddagger}$ Paola Leone, ${ }^{\star \ddagger}$ Karen E. Davis, ${ }^{\star \star}$ David Kerr, ${ }^{*}$ and Robert S. Sherwin \\ Molecular Pharmacology and Neurogenetics Laboratory, Sections of *Endocrinology and ${ }^{\ddagger}$ Neurosurgery, Departments of Medicine \\ and Surgery, Yale University School of Medicine, New Haven, Connecticut 06520-8039
}

\section{Abstract}

Glucose modulates beta cell insulin secretion via effects on ATP-sensitive potassium $\left(K_{\mathrm{ATP}}\right)$ channels. To test the hypothesis that glucose exerts a similar effect on neuronal function, local glucose availability was varied in awake rats using microdialysis in the substantia nigra, the brain region with the highest density of $K_{A T P}$ channels. $10 \mathrm{mM}$ glucose perfusion increased GABA release by $111 \pm 42 \%$, whereas the sulfonylurea, glipizide, increased GABA release by $84 \pm 20 \%$. In contrast, perfusion of the $K_{A T P}$ channel activator, lemakalim, or depletion of ATP by perfusion of 2-deoxyglucose with oligomycin inhibited GABA release by $44 \pm 8$ and $45 \pm 11 \%$, respectively. Moreover, the inhibition of GABA release by 2-deoxyglucose and oligomycin was blocked by glipizide.

During systemic insulin-induced hypoglycemia (1.8 \pm 0.3 $\mathrm{mM}$ ), nigral dialysate GABA concentrations decreased by $49 \pm 4 \%$ whereas levels of dopamine in striatal dialysates increased by $119 \pm 18 \%$.

We conclude that both local and systemic glucose availability influences nigral GABA release via an effect on $K_{\text {ATP }}$ channels and that inhibition of GABA release may in part mediate the hyperexcitability associated with hypoglycemia. These data support the hypothesis that glucose acts as a signaling molecule, and not simply as an energy-yielding fuel, for neurons. (J. Clin. Invest. 1995. 95:2403-2408.) Key words: ATP-sensitive potassium channels • substantia nigra - glucose • GABA • sulfonylureas

\section{Introduction}

A group of potassium channels has been shown to be sensitive to alterations in the intracellular concentration of ATP and the

Address correspondence to Dr. M. J. During, Yale Medical School, 333 Cedar Street, P.O. Box 208039, New Haven, CT 06520-8039. Phone: 203-785-4786; FAX: 203-785-6916.

Received for publication 6 October 1994 and in revised form 6 January 1995.

J. Clin. Invest.

(C) The American Society for Clinical Investigation, Inc.

$0021-9738 / 95 / 05 / 2403 / 06 \$ 2.00$

Volume 95, May 1995, 2403-2408 ratio of ATP to ADP. These ATP-sensitive potassium $\left(\mathrm{K}_{\mathrm{ATP}}\right)^{1}$ channels have been described in pancreatic islets (1), cardiac myocytes $(2,3)$, vascular smooth muscle (4), and skeletal muscle (5). Furthermore, these channels are also expressed in the brain. Sulfonylureas bind potently and specifically to $K_{\mathrm{ATP}}$ channels $(6,7)$, although the precise stoichiometry of the relationship between sulfonylureas and $\mathbf{K}_{\mathrm{ATP}}$ channels is not known. However, the channel forms a single functional moiety with the sulfonylurea receptor in neurons (8), and using autoradiography of labeled sulfonylureas the distribution of $\mathrm{K}_{\mathrm{ATP}}$ channels has been indirectly mapped. Sulfonylurea binding sites are widely distributed throughout the brain and in the rodent are most abundant in the substantia nigra pars reticulata (9-14).

ATP-sensitive potassium channels have been best characterized in the endocrine pancreas where they mediate the effect of glucose on insulin release from $\beta$ cells. In vitro experiments have demonstrated that the channels are inhibited by high levels of glucose as well as by sulfonylureas resulting in depolarization and insulin release $(15,16)$. In contrast, when intracellular levels of ATP and/or the ATP/ADP ratio falls, $\mathrm{K}_{\mathrm{ATP}}$ channels are activated, leading to hyperpolarization and inhibition of insulin release $(17-19)$. In the heart these channels mediate in part the vasodilatory response to hypoxia $(4,20)$. However, the role of these channels in neurons is less evident. It has been postulated that $\mathrm{K}_{\mathrm{ATP}}$ channels may mediate responses to ischemia and hypoxia (21-23) and may perhaps control neuronal excitability and seizure generation (24).

Of interest is the hypothesis of Lazdunski and his colleagues (24) that the $\mathrm{K}_{\mathrm{ATP}}$ channel may be a direct link between intermediary metabolism and neuronal excitability. They postulated that since these channels are highly expressed presynaptically in the GABAergic pallidonigral projection to the substantia nigra pars reticulata that hypoglycemia by depleting intracellular ATP would open the $\mathrm{K}_{\mathrm{ATP}}$ channels, hyperpolarizing these inhibitory GABA terminals, thereby producing disinhibition of the ascending mesostriatal dopamine pathway (24). Although seizures do not generate from the substantia nigra, this nucleus appears to have a major gating role in convulsive seizures. A critical level of GABA within the substantia nigra appears necessary to prevent seizure generalization $(25,26)$. This theory is attractive as it would explain the association between hypoglycemia and clinical seizures.

To test this hypothesis directly we used microdialysis to alter local glucose availability and to pharmacologically characterize the effects of specific $K_{\mathrm{ATP}}$ channel agonists and antago-

1. Abbreviations used in this paper: ECF, extracellular fluid; $\mathrm{K}_{\mathrm{ATP}}$, ATP-sensitive potassium channels. 
nists on GABA release in vivo. Moreover, we also investigated the effect of systemic hypoglycemia using the insulin-clamp method on both nigral GABA and striatal dopamine release in the freely moving rat.

\section{Methods}

\section{Animals}

Male Sprague-Dawley rats (weighing 280-300 g) were used for all experiments. Animals were grouped housed in an animal facility with controlled lighting (12-h light/dark cycle) and humidity and ad libitum access to water and standard rat chow (Prolab 3000, comprising of 22\% protein, $5 \%$ fat, and $51 \%$ carbohydrate; Agway, Waverly, NY). On the evening before study, the rat chow was removed and animals were allowed free access to water only.

\section{Microdialysis}

Freely moving microdialysis was performed as described previously $(27,28)$. In brief, groups of animals were implanted with guide cannulae for placement of concentric microdialysis probes at least $1 \mathrm{wk}$ before dialysis perfusion. In one group of rats the cannula was implanted above the right substantia nigra (AP 3.5, ML 2.15, DV -6 from lambda flat skull [29]) to alter glucose availability and to pharmacologically manipulate $\mathrm{K}_{\mathrm{ATP}}$ channels locally. The second group had both the nigra guide cannula as well as a second cannula implanted above the ipsilateral corpus striatum at coordinates relative to bregma, AP 1.2, ML 2.6, DV -3 (29). These animals underwent insulin hypoglycemic studies as described below. The nigral microdialysis probes were of concentric design, with $2 \mathrm{~mm}$ of exposed membrane spanning DV coordinates of 7 to $9 \mathrm{~mm}$ from the bregma-lambda plane. The striatal probes were constructed similarly, but used $4 \mathrm{~mm}$ of exposed membrane, which after implantation spanned DV coordinates of 3 to $7 \mathrm{~mm}$ from the bregmalambda plane.

All probes were inserted via the previously implanted guide cannulae 18-24 $\mathrm{h}$ before the microdialysis study. The probes were connected using vitreous silica tubing to $1-\mathrm{ml}$ syringes mounted on a Harvard perfusion pump (model 22; Harvard Instruments, South Natick, MA). The dialysis system was perfused at $1 \mu \mathrm{l} / \mathrm{min}$ with sterilized, pyrogenfree artificial extracellular fluid (ECF) of the following composition: $\mathrm{NaCl}(135 \mathrm{mM}), \mathrm{KCl}(3 \mathrm{mM}), \mathrm{MgCl}_{2}(1.0 \mathrm{mM}), \mathrm{CaCl}_{2}(1.2 \mathrm{mM})$, ascorbate $(200 \mu \mathrm{M})$, and sodium mono- and dibasic phosphate $(2 \mathrm{mM})$ to $\mathrm{pH}$ 7.4. Drugs and glucose were perfused locally over two 30 -min collection periods. Drugs used in the dialysis protocols included: glucose (10 $\mathrm{mM})$, the sulfonylurea, glipizide $(50 \mu \mathrm{M}), 2$-deoxyglucose (10 $\mathrm{mM}$ ), oligomycin $(30 \mu \mathrm{M})$, and the specific $\mathrm{K}_{\mathrm{ATP}}$ channel activator, lemakalim $(200 \mu \mathrm{M})$.

All drugs were obtained from Sigma Immunochemicals (St. Louis, MO), except for lemakalim which was kindly provided by SmithKline Beecham Pharmaceuticals (King of Prussia, PA) and glipizide which was obtained from Pfizer (Groton, CT).

\section{No net flux quantification of absolute extracellular concentrations}

The previously established method of no net flux $(30,31)$ was used to quantitate absolute extracellular levels of glucose in the substantia nigra in fasting rats. In brief, this method is based on the concentration gradient between the dialysate fluid and the ECF of the brain driving the compound of interest (glucose) from dialysate to brain or brain to dialysate. When the dialysis perfusion fluid contains glucose at a concentration greater than that of ECF, then the outlet concentration of glucose in the dialysate is lower than that of the inlet (perfusing) solution. When the ECF glucose concentration is greater than that of the inlet solution, then the outlet glucose concentration is greater than the perfusing solution. When the inlet equals the outlet concentration, i.e., no net flux of glucose across the dialysis membrane, then the dialysate concentration is equal to the ECF concentration.

\section{Hypoglycemic insulin-clamp study}

$5 \mathrm{~d}$ before study, a group of rats underwent aseptic surgery for placement of catheters in both the internal jugular and carotid artery under intraperitoneal Nembutal anesthesia $\left(30 \mathrm{mg} \mathrm{kg}^{-1}\right)$. The polyethylene carotid artery catheter was extended to the level of the aortic arch and the silicone internal jugular vein catheter was advanced to the level of the right atrium. The catheters were filled with heparin $(42 \mathrm{U} / \mathrm{ml})$ and polyvinylpyrrolidone $(1.7 \mathrm{mg} / \mathrm{ml})$ solution, then plugged and tunneled subcutaneously around the side of the neck and externalized posteriorly through a skin incision. Only animals that recovered from surgery with normal motor and ingestive behavior were used for further study.

On the morning of the experiment, the catheters were flushed with $0.9 \%$ saline and maintained patent by slow perfusion of saline (containing $1 \mathrm{U} / \mathrm{ml}$ heparin) at $8 \mu \mathrm{l} / \mathrm{min}$. Animals were awake and freely moving throughout the study. After a 60-min rest period, blood samples were withdrawn for measurement of baseline glucose. At time 0 , a continuous infusion of insulin was started (regular porcine insulin; Eli Lilly \& Co., Indianapolis, IN) and maintained for $120 \mathrm{~min}$. The perfusion rate ranged from 75 to $80 \mathrm{pmol} / \mathrm{kg} \mathrm{min}^{-1}$. Plasma glucose was determined every 5 min throughout the insulin infusion and a variable infusion of $25 \%$ dextrose (in sterile water) was adjusted to maintain a stable hypoglycemic plateau. Thereafter the insulin was discontinued and the plasma glucose was raised to baseline values over a $30-\mathrm{min}$ period. For a 120-min period before, during, and for a $80-\mathrm{min}$ period after the insulin infusion, nigral and striatal dialysate were monitored for GABA and dopamine, respectively.

\section{Analysis}

Glucose. Plasma glucose was measured using a Beckman Glucose Analyzer II (Beckman Instruments, Inc., Fullerton, CA). Dialysate glucose was measured using an isocratic HPLC system using a $150 \times 3-\mathrm{mm}$ phase II $3-\mu \mathrm{m}$ ODS analytical column linked directly to a glucose oxidase enzyme reactor with $\mathrm{H}_{2} \mathrm{O}_{2}$ detected on a platinum electrode at $450 \mathrm{mV}$ (BAS 200; BAS Bioanalytical Systems, Inc., West Lafayette, IN). The mobile phase consisted of $50 \mathrm{mM}$ sodium phosphate buffer ( $\mathrm{pH} 8.5$ ) with $0.5 \%$ Kathon reagent microbiocide (BAS, West Lafayette, IN) and was pumped at $0.6 \mathrm{ml} / \mathrm{min}$.

$G A B A$. GABA was measured using an isocratic HPLC system with fluorometric detection based on the method of Durkin (32). The mobile phase consisted of $0.57 \mathrm{M}$ acetic acid ( $\mathrm{pH} \mathrm{3.78)}$ with $25 \%$ acetonitrile and 12\% tetrahydrofuran. An AD10 HPLC pump (Shidmazu Scientific Instruments, Inc., Columbia, MD) pump was used isocratically at 0.6 $\mathrm{ml} / \mathrm{min}$ with separation on a $150 \times 3-\mathrm{mm}, 3-\mu \mathrm{m}$ ODS column (Keystone Scientific, Inc., Bellefonte, PA). Fluorometric detection was obtained using a Shidmazu model 551 detector (excitation $330 \mathrm{~nm}$, emission $440 \mathrm{~nm}$ ). $5 \mu \mathrm{l}$ of the dialysis sample was derivatized with $3 \mu \mathrm{l}$ of an $o$-pthaladehyde/mercaptopropionic acid reagent and $7.5 \mu 1$ was injected after a 90-s reaction time using a refrigerated autoinjector (CMA200; Carnegie Medicine, Stockholm, Sweden). A stock reagent was made monthly by adding $10 \mathrm{mg} o$-pthaladehyde to $4.5 \mathrm{ml}$ methanol and $0.5 \mathrm{ml}$ of a $0.5 \mathrm{mM}$ borate ( $\mathrm{pH} \mathrm{9.5)} \mathrm{buffer} \mathrm{to} \mathrm{which} 25 \mu \mathrm{l}$ of mercaptopropionic acid was added. The working reagent was made daily of $100 \mu \mathrm{l}$ of methanol, $100 \mu \mathrm{l}$ of borate buffer, and $36 \mu \mathrm{l}$ of the stock reagent.

\section{Statistics}

All data are reported as the mean \pm standard error of the mean (SEM). All comparisons were made using the Systat v. 5.2.1 (Evanston, IL) software using repeated measures ANOVA and posthoc tests including Fisher PLSD and Tukey's tests.

\section{Results}

Effect of raising local nigral glucose concentration. The basal nigral glucose level in microdialysates of fasted rats was $0.27 \pm 0.06 \mathrm{mM}$. Using the no net flux method, absolute ECF levels were $1.4 \pm 0.3 \mathrm{mM}$, reflecting a $19 \%$ in vivo probe effi- 

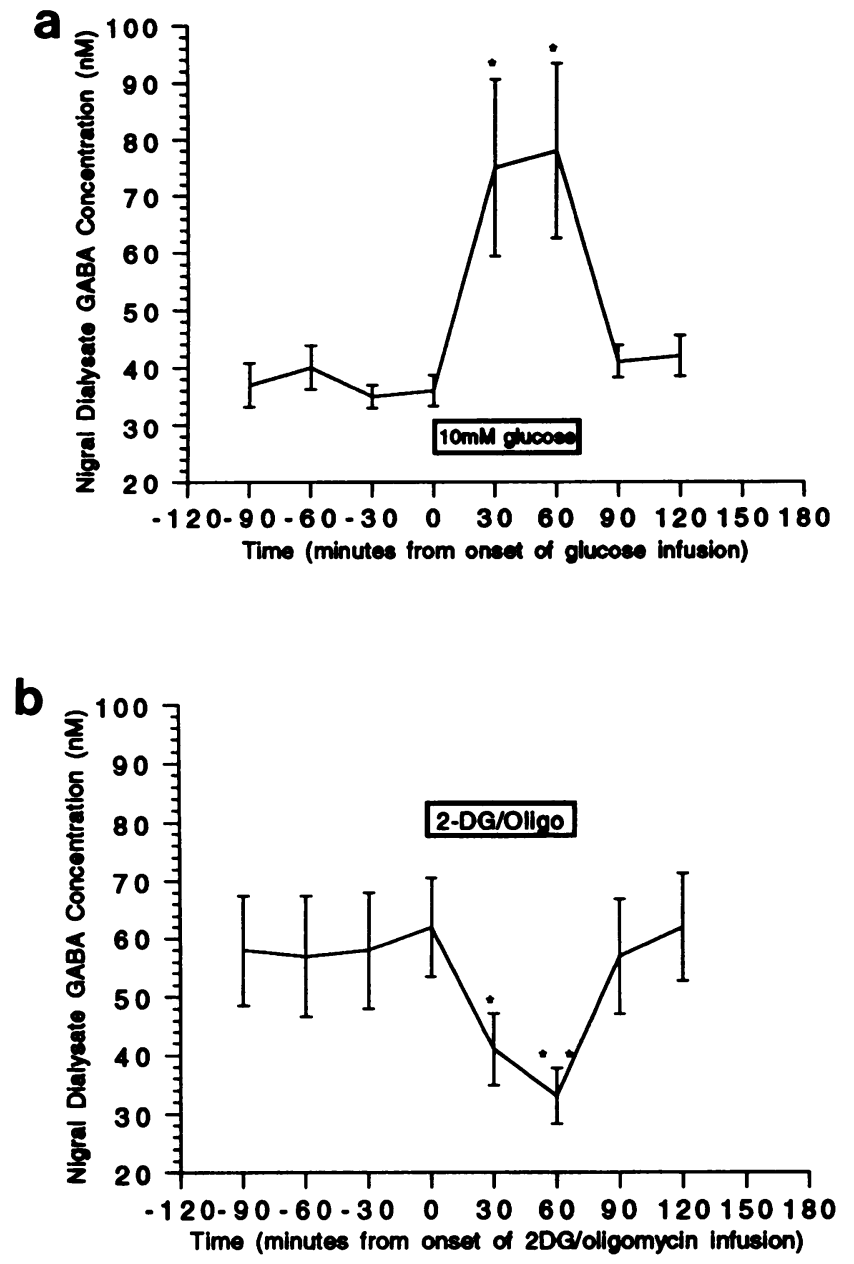

Figure 1. Baseline nigral dialysate GABA levels were obtained 18-24 $\mathrm{h}$ after probe placement in the freely moving rat. The perfusion fluid was changed to include $(a) 10 \mathrm{mM}$ glucose for $60 \mathrm{~min}$ and then changed back to the regular (glucose-free) artificial extracellular fluid $(n=6)$, or (b) $10 \mathrm{mM}$ 2-deoxyglucose and $30 \mu \mathrm{M}$ oligomycin B perfused for $60 \mathrm{~min}$ followed by return to perfusion with the regular (glucose-free) ECF $(n=4) .{ }^{*} P<0.05,{ }^{* *} P<0.01$, ANOVA with repeated measures and posthoc tests.

ciency (the ratio of dialysate concentration to absolute ECF concentration) at $1 \mu \mathrm{l} / \mathrm{min}$.

Increasing dialysate glucose to $10 \mathrm{mM}$ resulted in a net flux of glucose from the dialysate into brain; the dialysis outflow concentration was $\sim 8 \mathrm{mM}$. Over $60 \mathrm{~min}$ of microdialysis perfusion, $\sim 0.18 \mu \mathrm{mol}$ of glucose was delivered locally, raising ECF glucose levels to $\sim 10 \mathrm{mM}$ at the outer membrane of the probe, with a gradient to resting level $(\sim 1.4 \mathrm{mM}$ as determined above) over several hundred microns radiating from the dialysis membrane (33). This increase in local ECF glucose resulted in a $111 \pm 42 \%$ increase in nigral dialysate GABA concentrations from basal levels of $37 \pm 3 \mathrm{nM}(P<0.01)$ (Fig. $1 a)$.

Effect of local perfusion with 2-deoxyglucose and oligomycin. The microdialysis probe was perfused with 2-deoxyglucose and oligomycin $B$. The concentrations used have been shown previously to block glucose metabolism and deplete tissue ATP levels (24). Dialysate concentrations of GABA decreased with a nadir of $44 \pm 8 \%$ below basal values reached at $60 \mathrm{~min}$ (Fig. $1 b)$.
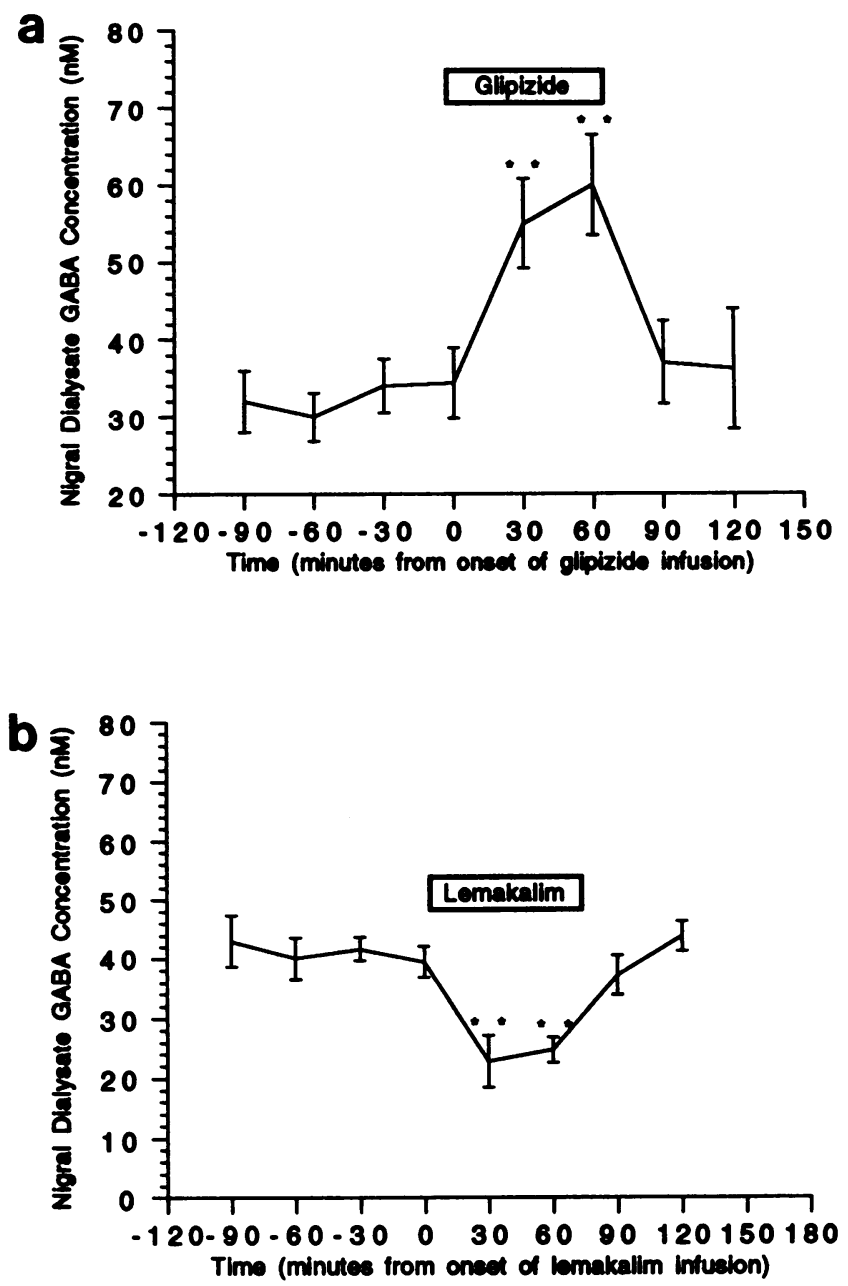

Figure 2. Baseline nigral dialysate GABA levels were obtained 18-24 $h$ after probe placement in the freely moving rat. The perfusion fluid was changed to include $(a) 50 \mu \mathrm{M}$ glipizide for $60 \mathrm{~min}$ and then changed back to the regular ECF $(n=5)$, or $(b) 200 \mu \mathrm{M}$ lemakalim for $60 \mathrm{~min}$ and then changed back to regular ECF $(n=6)$. ${ }^{*} P<0.05, * * P$ $<0.01$, ANOVA with repeated measures and posthoc tests.

Effect of local perfusion of glipizide and lemakalim. The $K_{\mathrm{ATP}}$ channel antagonist, glipizide, increased dialysate GABA, reaching peak levels of $84 \pm 20 \%$ above baseline $(P<0.01)$ at 60 min (Fig. $2 a$ ). In contrast, the $\mathrm{K}_{\mathrm{ATP}}$ channel agonist, lemakalim, promptly reduced dialysate GABA concentrations measured from the nigral probe. Dialysate GABA concentrations declined by $45 \pm 11 \%(P<0.01)$ at $30 \mathrm{~min}$ (Fig. $2 b)$. At the end of the 60-min drug perfusion period, dialysate GABA rapidly returned to baseline values, regardless of whether an agonist or antagonist was used.

In addition, glipizide was locally perfused for $150 \mathrm{~min}$, and after $90 \mathrm{~min}$ 2-deoxyglucose and oligomycin were added during the final $60 \mathrm{~min}$ of the study. In the initial phase, glipizide increased dialysate GABA from $38 \pm 3$ to $51 \pm 5 \mathrm{nM}(P<0.05)$. The subsequent addition of 2-deoxyglucose and oligomycin had no inhibitory effect on nigral GABA release (Fig. 3).

Effect of systemic hypoglycemia. Before the combined intravenous insulin/glucose infusion basal glucose levels averaged $5.4 \pm 0.3 \mathrm{mM}$. During the insulin hypoglycemic phase plasma glucose concentration was clamped at $\sim 2 \mathrm{mM}$ for a period 


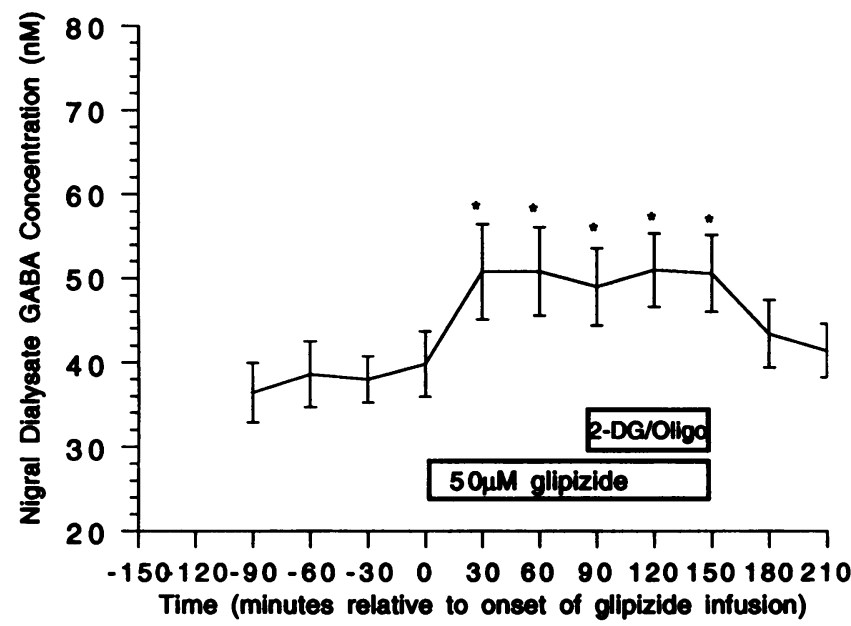

Figure 3. Baseline nigral dialysate GABA levels were obtained 18-24 $\mathrm{h}$ after probe placement in the freely moving rat. The perfusion fluid was changed to include $50 \mu \mathrm{M}$ glipizide for $90 \mathrm{~min}$ and then changed to include both $50 \mu \mathrm{M}$ glipizide and $10 \mathrm{mM}$ 2-deoxyglucose and 30 $\mu \mathrm{M}$ oligomycin $\mathrm{B}$ for an additional $60 \mathrm{~min}$ before reperfusion with the regular artificial extracellular fluid $(n=5) .{ }^{*} P<0.01$ from basal values, ANOVA with repeated measures and posthoc tests.

of $100 \mathrm{~min}$ (Fig. $4 \mathrm{a}$ ). Dialysate GABA levels progressively decreased after the start of the insulin infusion. The GABA concentration nadir was reached $30 \mathrm{~min}$ before the end of the hypoglycemic period, amounting to a decrease of $49 \pm 4 \%$ below basal levels (Fig. $4 \mathrm{~b}$ ). In contrast, striatal dopamine levels increased reaching a peak at $75 \mathrm{~min}$, an increase of $119 \pm 18 \%$ above basal values (Fig. $4 c$ ).

\section{Discussion}

These data suggest that glucose availability influences in vivo GABA release via $K_{\mathrm{ATP}}$ channels and that glucose is not merely a metabolic fuel in the brain but has a direct effect on neurotransmission. Microdialysis perfusion of $1.4 \pm 0.3 \mathrm{mM}$ glucose resulted in no net flux of glucose into the brain, an estimate of absolute (spatially averaged) extracellular glucose $(30,31)$. This level of glucose was $26 \pm 6 \%$ that of the fasting plasma levels. Siesjo (34) and Lund-Andersen (35) have proposed that brain ECF glucose levels are $2-4 \mathrm{mM}$ similar to cerebrospinal fluid levels of glucose. Our data suggest that ECF glucose is significantly lower than cerebrospinal fluid levels. Moreover, using microdialysis in conscious humans (36-38) we obtained dialysate levels of glucose of $500 \mu \mathrm{M}$ with absolute extracellular levels determined by the no net transfer method (30) of 1.4$1.7 \mathrm{mM}$ when fasting plasma glucose was stable at 4.7$5.6 \mathrm{mM}$.

The perfusion of $10 \mathrm{mM}$ glucose resulted in a net flux of glucose into the brain ECF. This local delivery of glucose resulted in an increase in nigral GABA release. In contrast, local perfusion of 2-deoxyglucose and oligomycin at concentrations shown to produce depletion of ATP (24) resulted in a significant reduction in GABA release. This pattern of stimulated GABA release to high concentrations of glucose and inhibition of release with low glucose confirms in vitro data using slices of rat substantia nigra (24). Moreover, our results using drugs which act on the $\mathrm{K}_{\mathrm{ATP}}$ channel are consistent with previously described
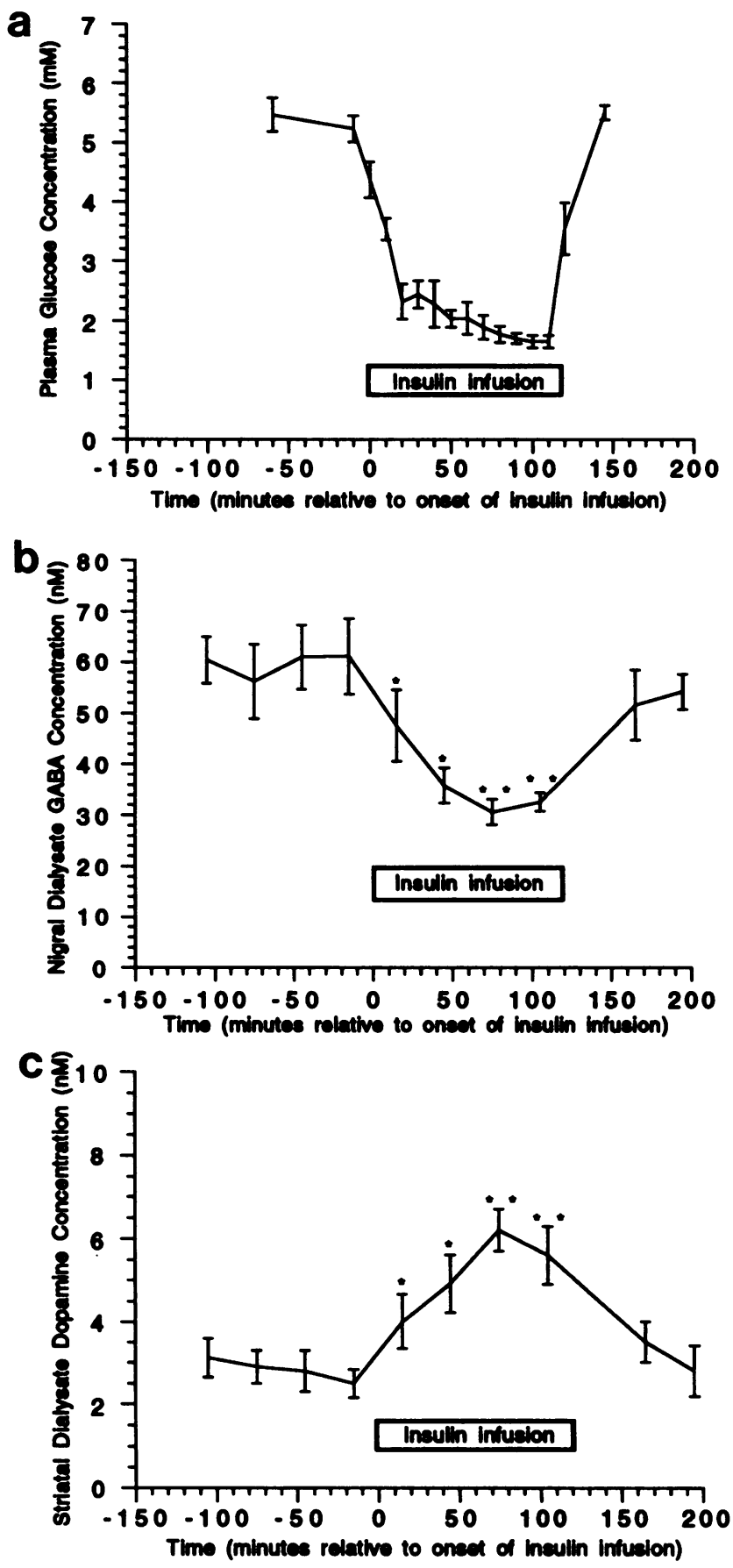

Figure 4. Combined intravenous insulin/glucose infusion was used to generate a controlled hypoglycemia. Insulin perfusion was commenced at time 0 after an overnight fast and stable basal plasma glucose levels of $5.4 \pm 0.3 \mathrm{mM}$. Rats $(n=5)$ were clamped during the hypoglycemic phase at a plasma glucose concentration of $1.8 \pm 0.3 \mathrm{mM}$. This level of hypoglycemia was maintained for $70 \mathrm{~min}(a)$. Simultaneous nigral and striatal microdialysis were performed. GABA levels in the nigral dialysates are represented in $b$ and dopamine levels in the striatal dialysate are represented in $c{ }^{*} P<0.05,{ }^{*} P<0.01$, ANOVA with repeated measures and posthoc tests.

pharmacological responses in both $\beta$ cells and the nigral slice preparation. Although ATP-sensitive $\mathrm{K}^{+}$channel openers have generally been shown to have nonspecific effects on calcium 
channels and act on other types of $\mathrm{K}^{+}$channels, lemakalim, unlike its racemate cromakalim, may have greater specificity for ATP-sensitive potassium channels (39). Therefore, the response to lemakalim supports the hypothesis that brain GABA release can be modulated in vivo by drugs which act on the $K_{A T P}$ channel. Furthermore, the sulfonylurea, glipizide, is a potent inhibitor of the $K_{A T P}$ channel (24) and at low concentrations produced significant elevations in GABA levels. Moreover, glipizide completely antagonized the effect of 2-deoxyglucose and oligomycin on GABA release. These data therefore suggest that ATP depletion obtained by local infusion of 2-deoxyglucose and oligomycin inhibits GABA release in part via an effect on $\mathrm{K}_{\mathrm{ATP}}$ channels. Our pharmacological data are also consistent with those of Politi and Rogawski (40). These authors used whole cell voltage-clamp recording in cultured hippocampal neurons to demonstrate the presence of channels activated by cromakalim and 2DG/oligomycin and blocked by the sulfonylurea, glyburide. Their in vitro electrophysiological results directly parallel our in vivo neurochemical data.

In addition to the effect of local manipulation of interstitial concentrations of glucose, the systemic infusion of insulin and glucose to obtain stable hypoglycemia $(1.8 \pm 0.3 \mathrm{mM})$ inhibited nigral GABA release and simultaneously increased striatal dopamine release suggesting a disinhibition of nigrostriatal neurons. In vivo extracellular recording studies have shown that elevated levels of plasma glucose suppress the firing of mesencephalic dopaminergic neurons (41). Although the effect of hypoglycemia on dopaminergic neuron firing has not been reported, biochemical studies have shown that hypoglycemia increases striatal dopamine turnover (42). In contrast, chronic hyperglycemia as obtained in diabetic rats reduces nigrostriatal dopamine turnover (43).

Our data thus suggest that changes in intermediary metabolism and specifically the brain availability of glucose and its extracellular concentration influence neuronal function. Although our data strongly suggest that low glucose and depletion of ATP inhibits GABA release via an action on ATP-sensitive potassium channels, it is possible that the effect of high glucose on GABA release may occur independently of $K_{A T P}$ channels. For example, glucose might act in a nonspecific manner as a nutrient, although the mechanism of how such a nutrient effect would translate to neurotransmitter release is unknown. A glucose-stimulated increase in ECF GABA would still require the involvement of a release apparatus including presumably an effect on channel opening or conductance resulting in membrane depolarization. Alternatively, glucose might affect GABA uptake, although there are no data that GABA transporters are inhibited by elevated glucose or increased ATP. Our interpretation that elevated glucose increases transmitter release via $K_{\text {ATP }}$ channels is also consistent with the neurochemical in vitro data (24). Of interest are recent data by van der Kuil and Korf (44) and Fellows and Boutelle (45) of changes in extracellular glucose associated with an alteration in neuronal activity. Specifically, van der Kuil reported an increase in hippocampal glucose associated with restraint stress in rodents, whereas Fellows and Boutelle showed that local neuronal depolarization with veratridine lowered extracellular glucose, whereas tetrodotoxin (which acts to block action potentials) increased extracellular glucose. These data suggest that glucose may act as a paracrine factor in the ECF and that dynamic changes in the level of extracellular glucose by local neuronal activity provide an additional mechanism to modulate local brain function. Our data suggest that an increase in extracellular glucose resulting from decreased neuronal activity might increase intraneuronal ATP/ ADP ratios and block $K_{A T P}$ channels, thereby resulting in depolarization and neurotransmitter release. The effect on brain function of such elevation, and reciprocally the effect of low glucose, would be dependent on the cellular location of these $K_{\text {ATP }}$ channels. Specifically the presence of the $K_{A T P}$ channels on presynaptic GABA terminals would produce hyperexcitability and lower the seizure threshold during hypoglycemia (and low brain interstitial glucose concentrations), whereas elevated interstitial glucose concentrations would produce increased inhibition. Although this hypothesis supports the association of clinical seizures precipitated by hypoglycemia, $\mathrm{K}_{\mathrm{ATP}}$ channels are expressed in excitatory neurons (13) in addition to their expression on inhibitory GABAergic neurons. The net effect on neuronal excitability of alterations in systemic glucose availability might reflect the relative abundance of these channels on inhibitory (GABA) neurons versus excitatory (predominantly glutamatergic) neurons. The intracerebroventricular administration of $\mathrm{K}_{\mathrm{ATP}}$ channel activators exhibits significant antiepileptic activity $(46,47)$. This effect is unlikely to be mediated by hyperpolarization and inhibition of nigral GABA release but it is consistent with expression of $\mathrm{K}_{\mathrm{ATP}}$ channels on excitatory, glutamatergic neurons $(13,48)$. Although expression of $K_{A T P}$ channels in primates in general parallels the expression in rodents (12), the heterogeneity of expression is much less, suggesting these channels have a more global action in the primate brain.

In summary our data suggest that pharmacological manipulation of the ATP-sensitive potassium channel affects nigral GABA release in vivo. Furthermore, alterations in brain glucose availability influence both GABA and striatal dopamine release in vivo, an effect which may in part be mediated via $K_{\text {ATP }}$ channels. As brain interstitial glucose levels inversely correlate with neuronal activity in both rodent (49) and human brain (During, M. J., unpublished data), these channels may function largely in a homeostatic manner, with increased neuronal activity depleting interstitial glucose, decreasing the intracellular ATP/ADP ratio, and thereby opening the $K_{\text {ATP }}$ channel and hyperpolarizing the neuron. This hypothesis is consistent with recent data showing protection of global ischemia-induced neuronal death by centrally administered potassium channel openers (50).

\section{Acknowledgments}

We thank Kristina Burns and Gautam Mirchandani for technical assistance.

This work was supported in part by National Institutes of Health grants DK-20495, NS-28227, and NS-06208, a Johnson \& Johnson Focused Giving Award to M. J. During, and the Juvenile Diabetes Foundation.

\section{References}

1. Findlay, I., M. J. Dunne, and O. H. Petersen. 1985. ATP-sensitive inward rectifier and voltage- and calcium-activated $\mathrm{K}^{+}$channels in cultured pancreatic cells. J. Membr. Biol. 88:165-172.

2. Noma, A. 1983. ATP-regulated $\mathrm{K}^{+}$channels in cardiac muscle. Nature (Lond.). 305:147-148.

3. Kakei, M., A. Noma, and T. Shibasaki. 1985. Properties of adenosinetriphosphate-regulated potassium channels in guinea-pig ventricular cells. J. Physiol. $363: 441-462$.

4. Standen, N. B., J. M. Quayle, N. W. Davies, J. E. Brayden, Y. Huang, 
and M. T. Nelson. 1989. Hyperpolarizing vasodilators activate ATP-sensitive $K$ channels in arterial smooth muscle. Science (Wash. DC). 245:177-180.

5. Spruce, A. E., N. B. Standen, and P. R. Stanfield. 1985. Voltage-dependent ATP-sensitive potassium channels of skeletal muscle membrane. Nature (Lond.). 316:736-738.

6. Schmid-Antomarchi, H., J. R. de Weille, M. Fosset, and M. Lazduski. 1987. The receptor for antidiabetic sulfonylureas controls the activity of the ATPmodulated K channel in insulin-secreting cells. J. Biol. Chem. 262:15840-15844.

7. Aguilar-Bryan, L., C. G. Nichols, A. S. Rajan, C. Parker, and J. Bryan. 1992. Co-expression of sulfonylurea receptors and K-ATP channels in hamster insulinoma tumor (HIT) cells-evidence for direct association of the receptor with the channel. J. Biol. Chem. 267:14934-14940.

8. Bernardi, H., M. Fosset, and M. Lazdunski. 1992. ATP/ADP binding sites are present in the sulfonylurea binding protein associated with brain ATP-sensitive K channels. Biochemistry. 31:6328-6332.

9. Mourre, C., Y. Ben-Ari, H. Bernardi, M. Fosset, and M. Lazdunski. 1989. Antidiabetic sulfonylureas: localization of binding sites in the brain and effects on the hyperpolarization induced by anoxia in hippocampal slices. Brain Res. 486:159-164.

10. Zini, S., E. Tremblay, M. Roisin, and Y. Ben-Ari. 1991. Regional distribution of sulfonylurea receptors in the brain of rodent and primate. Brain Res. 542:151-154.

11. Zini, S., Y. Ben-Ari, and M. L. J. Ashford. 1991. Characterization of sulfonylurea receptors and the action of potassium channel openers on cholinergic neurotransmission in guinea-pig isolated small intestine. J. Pharmacol. Exp. Ther. 259:566-573.

12. Zini, S., E. Tremblay, H. Pollard, J. Moreau, and Y. Ben-Ari. 1993. Regional distribution of sulfonylurea receptors in the brain of rodent and primate. Neuroscience. 55:1085-1091.

13. Tremblay, E., S. Zini, and Y. Ben-Ari. 1991. Autoradiography study of the localization of $\left[{ }^{3} \mathrm{H}\right]$ glibenclamide binding sites in the rat brain. Neurosci. Lett. 127:21-24.

14. Xia, Y., and G. G. Haddad. 1991. Major differences in CNS sulfonylurea receptor distribution between the rat (newborn, adult) and turtle. J. Comp. Neurol. 314:278-289.

15. Petersen, O. H., and M. J. Dunne. 1989. Regulation of $\mathbf{K}$ channels plays a crucial role in the control of insulin secretion. Pflueg. Arch. Eur. J. Physiol. 414:S115-S120.

16. Petersen, O. H., and I. Findlay. 1987. Electrophysiology of the pancreas. Physiol. Rev. 67:1054-1116.

17. Sofue, M., Y. Yoshimura, M. Nishida, and J. Kawada. 1991. Uptake of nicotinamide by rat pancreatic beta cells with regard to streptozotocin action. $J$. Endocrinol. 131:135-138.

18. Henquin, J. C. 1992. Adenosine triphosphate-sensitive K channels may not be the sole regulators of glucose-induced electrical activity in pancreatic Bcells. Endocrinology. 131:127-131.

19. Detimary, P., P. Gilon, M. Nenquin, and J. C. Henquin. 1994. Two sites of glucose control of insulin release with distinct dependence on the energy state in pancreatic B-cells. Biochem. J. 297:455-461.

20. Daut, J. W., N. Maier-Rudolph, G. Von Beckerath, G. Mehrke, K. Gunther, and L. Goedel-Meinen. 1990. Hypoxic dilation of coronary arteries is mediated by ATP-sensitive potassium channels. Science (Wash. DC). 247:1341-1344.

21. Ben-Ari, Y. 1989. Effect of glibenclamide, a selective blocker of an ATP $\mathrm{K}$ channel, on the anoxic response of hippocampal neurons. Pflueg. Arch. Eur. J. Physiol. 414:S111-S114.

22. Jiang, C., Y. Xia, and G. G. Haddad. 1992. ATP-sensitive K channels during anoxia: major differences between rat (newborn and adult) and turtle neurons. J. Physiol. 448:599-612.

23. Jiang, C., and G. G. Haddad. 1991. Effect of anoxia on intracellular and extracellular potassium activity in hypoglossal neurons in vitro. J. Neurophysiol. 66:103-111.

24. Amoroso, S., H. Schmid-Antomarchi, M. Fosset, and M. Lazdunski. 1990 Glucose, sulfonylureas and neurotransmitter release: Role of ATP-sensitive K channels. Science (Wash. DC). 247:852-854.

25. Gale, K. 1985. Mechanisms of seizure control mediated by GABA: role of the substantia nigra. Fed. Proc. 44:2414-2424.

26. Gale, K. 1986. Role of the substantia nigra in GABA-mediated anticonvulsant actions. Adv. Neurol. 44:343-364.

27. During, M. J., J. S. Craig, T. D. Hernandez, G. M. Anderson, and D. W.
Gallager. 1992. Effect of amygdala kindling on the in vivo release of GABA and 5-HT in the dorsal raphe nucleus in freely moving rats. Brain Res. 584:36-44.

28. During, M. J., J. R. Naegele, K. L. O'Malley, and A. I. Geller. 1994 Long-term behavioral recovery in Parkinsonian rats by an HSV vector expressing tyrosine hydroxylase. Science (Wash. DC). 266:1399-1403.

29. Paxinos, G., and C. Watson. 1986. The Rat Brain in Stereotaxic Coordinates. Academic Press, Inc., New York.

30. Lonnroth, P., P.-A. Jansson, and U. Smith. 1987. A microdialysis method allowing characterization of intercellular water space in humans. Am. J. Physiol. 253:E228-E231.

31. Hamberger, A., I. Jacobson, B. Nystrom, and M. Sandberg. 1991. Microdialysis sampling of the neuronal environment in basic and clinical research. J. Int. Med. 230:375-380.

32. Durkin, T. A., G. M. Anderson, and D. J. Cohen. 1988. High-performance liquid chromatographic analysis of neurotransmitter amino acids in brain. J. Chromatogr. 428:9-15.

33. Morrison, P. F., P. M. Bungay, J. K. Hsiao, I. N. Mefford, K. H. Dykstra, and R. L. Dedrick. 1991. Quantitative microdialysis. In Microdialysis in the Neurosciences. T. E. Robinson and J. B. Justice, Jr., editors. Elsevier Science Publishing Co., Inc., New York. 47-80.

34. Siesjo, B. K. 1978. Brain Energy Metabolism. John Wiley and Sons, Chicester, United Kingdom.

35. Lund-Andersen, H. 1979. Transport of glucose from blood to brain. Phys iol. Rev. 59:305-352.

36. During, M. J. 1991. In vivo neurochemistry of the conscious human brain: intrahippocampal microdialysis in epilepsy. In Microdialysis in the Neurosciences. T. E. Robinson and J. B. Justice, Jr., editors. Elsevier Science Publishing Co., Inc., New York. 425-442.

37. During, M. J., and D. D. Spencer. 1992. Adenosine: a potential mediator of seizure arrest and postictal refractoriness. Ann. Neurol. 32:618-624.

38. During, M. J., and D. D. Spencer. 1993. Extracellular hippocampal glutamate and spontaneous seizure in the conscious human brain. Lancet. 341:16071610.

39. Post, J. M., R. J. Stevens, K. M. Sanders, and J. R. Hume. 1991. Effect of cromakalim and lemakalim on slow waves and membrane currents in colonic smooth muscle. Am. J. Physiol. 260:C375-C382.

40. Politi, D. M., and M. A. Rogawski. 1991. Glyburide-sensitive K channels in cultured rat hippocampal neurons: activation by cromakalim and energy depleting conditions. Mol. Pharmacol. 40:308-315.

41. Saller, C. F., and L. A. Chiodo. 1980. Glucose suppresses basal firing and haloperidol-induced increases in the firing rate of central dopaminergic neurons. Science (Wash. DC). 210:1269-1271.

42. Milusheva, E., M. Doda, E. Pasztor, A. Lajtha, H. Sershen, and E. S Vizi. 1992. Regulatory interactions among axon terminals affecting the release of different transmitters from rat striatal slices under hypoxic and hypoglycemic conditions. J. Neurochem. 59:946-952.

43. Gupta, G., M. Azam, and N. Z. Baquer. 1992. Effect of experimental diabetes on the catecholamine metabolism in rat brain. J. Neurochem. 58:95100

44. van der Kuil, J., and J. Korf. 1991. On-line monitoring of extracellular brain glucose using microdialysis and a NADPH-linked enzymatic assay. J. Neurochem. 57:648-654.

45. Fellows, L. K., and M. G. Boutelle. 1993. Rapid changes in extracellular glucose levels and blood flow in the striatum of the freely moving rat. Brain Res. 604:225-231.

46. Gandolfo, G., C. Gottesmann, J.-N. Bidard, and M. Lazdunski. 1989. K channel openers prevent epilepsy induced by the bee venom peptide MCD. Eur J. Pharmacol. 159:329-334.

47. Gandolfo, G., S. Romettino, C. Gottesmann, G. van Luijtelaar, A. Coenen, J. N. Bidard, and M. Lazdunski. $1989 . \mathrm{K}^{+}$channel openers decrease seizures in genetically epileptic rats. Eur. J. Pharmacol. 167:181-183.

48. Mourre, C., C. Widmann, and M. Lazdunski. 1991. Specific hippocampal lesions indicate the presence of sulfonylurea binding sites assoiciated to ATP sensitive $\mathrm{K}$ channels both post-synaptically and on mossy fibers. Brain Res. 540:340-344.

49. Fellows, L. K., M. G. Boutelle, and M. Fillenz. 1992. Extracellular brain glucose levels reflect local neuronal activity: a microdialysis study in awake, freely-moving rats. J. Neurochem. 59:2141-2147.

50. Heurteaux, C., V. Bertaina, C. Widmann, and M. Lazdunski. 1993. K channel openers prevent global ischemia-induced expression of c-fos, c-jun, heat shock protein, and amyloid beta-protein precursor genes and neuronal death in rat hippocampus. Proc. Natl. Acad. Sci. USA. 90:9431-9435. 